Acta Crystallographica Section D

\section{Biological Crystallography}

ISSN 0907-4449

\section{Helen Walden}

Protein Structure and Function Laboratory, Cancer Research UK London Research Institute, Lincoln's Inn Fields, London WC2A 3PX, England

Correspondence e-mail: helen.walden@cancer.org.uk

\title{
Selenium incorporation using recombinant techniques
}

Using selenomethionine to phase macromolecular structures is common practice in structure determination, along with the use of selenocysteine. Selenium is consequently the most commonly used heavy atom for MAD. In addition to the well established recombinant techniques for the incorporation of selenium in prokaryal expression systems, there have been recent advances in selenium labelling in eukaryal expression, which will be discussed. Tips and things to consider for the purification and crystallization of seleno-labelled proteins are also included.

\section{Introduction}

In 1957, Cowie and Cohen demonstrated the ability of Escherichia coli to incorporate selenium instead of sulfur during protein biosynthesis (Cowie \& Cohen, 1957). Several decades later, this trick was exploited in the development of powerful phasing techniques to solve the phase problem in macromolecular crystallography (Hendrickson et al., 1990). Hendrickson first reported the possibility of using selenomethionine (SeMet) as a phasing tool in 1990 and the ease of incorporating selenium in recombinant systems has led to selenium being the first choice for multiple-wavelength (and single-wavelength) anomalous dispersion experiments (Figs. $1 a$ and $1 b$ ). Incorporating SeMet recombinantly produces modified protein without the structural disturbance commonly associated with heavy-atom incorporation and removes the need for time-consuming and challenging screening for heavyatom derivatives.

Since the advent of structural genomics (SG) and with the increasing output from SG consortia, it has become clear that SeMet labelling for structure determination is making a profound difference to structure determination (Figs. $1 c$ and $1 d$ ). In addition to being a powerful phasing tool, SeMet substitution is also useful for sequence assignment and chain tracing in crystallography. In some cases, it has been reported that SeMet-derived crystals diffracted to a higher resolution than the native counterpart (Koon et al., 2004; Li et al., 2008; Quevillon-Cheruel et al., 2004). In prokaryal systems incorporation of SeMet is often close to $100 \%$, particularly when a methionine-auxotrophic strain such as B834 is used (Leahy et al., 1992). However, some proteins are just not amenable to production in bacteria and therefore in more recent years the incorporation of selenium has been adapted from simple prokaryotic expression systems to eukaryal systems. There have been a number of successful cases of incorporation in eukaryotic systems, including yeast, insect cells and mammalian cells (Larsson et al., 2002; Lustbader et al., 1995; Bellizzi et
Received 9 February 2009

Accepted 21 September 2009 
al., 1999). Given that the overall cost of structure determination has been estimated at more than $£ 100000$ per structure (Chandonia \& Brenner, 2006), the additional costs associated with use of SeMet are relatively small and can be reduced by using a DL-SeMet mixture at double the concentration of the more expensive L-SeMet. The only real drawback of recombinant SeMet incorporation is yield of labelled protein. This article will outline some of the considerations for each system and discuss methods for checking incorporation and crystallization of the resulting protein.

\section{Prokaryotic systems}

By far the simplest and the most widely used system for the incorporation of selenium is prokaryal expression. The initial reports of SeMet labelling of recombinant proteins entailed growing a methionine-auxotrophic strain of E. coli (DL41) in minimal media supplemented with amino acids and SeMet (Hendrickson et al., 1990). This is a very successful approach, resulting in close to $100 \%$ Se substitution, and is often used for structural problems, typically using the BL21-derived auxotrophic strain B834 (DE3) available from Invitrogen, Novagen, Stratagene and others. However, there are some disadvantages to the method as the yield of protein is often only $15-20 \%$ of that of the native protein. Also, growing E. coli in minimal media is time-consuming as it will often take up to $24 \mathrm{~h}$ for cultures to reach a cell density of $\mathrm{OD}_{600 \mathrm{~nm}}=0.6$. However, non-auxotrophic strains can be used to reliably incorporate selenium, albeit slightly less efficiently (Van Duyne et al., 1993; Doublié, 1997, 2007). If methionine biosynthesis is inhibited shortly before induction, $>90 \%$ SeMet incorporation can be observed. Inhibition of Met biosynthesis can be achieved by the use of high concentrations of isoleucine, leucine, phenylalanine, lysine and threonine, which

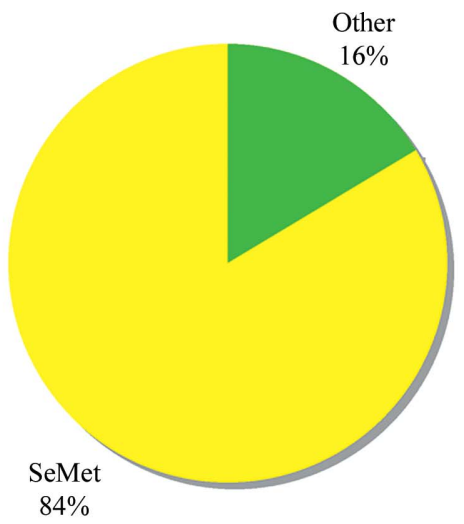

(a)

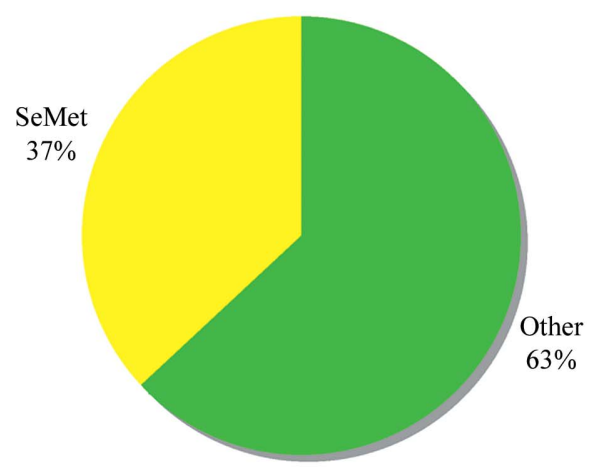

(c)

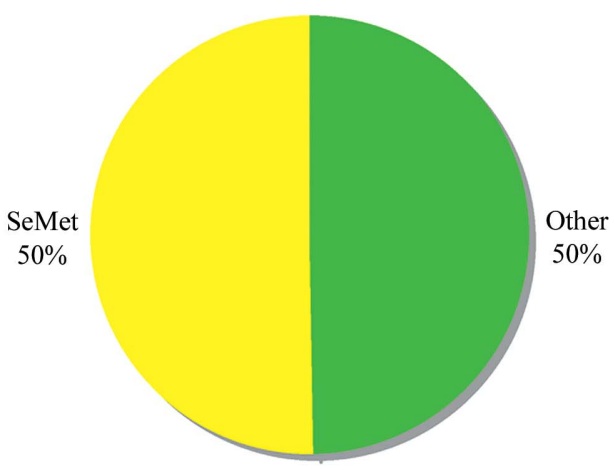

(b)

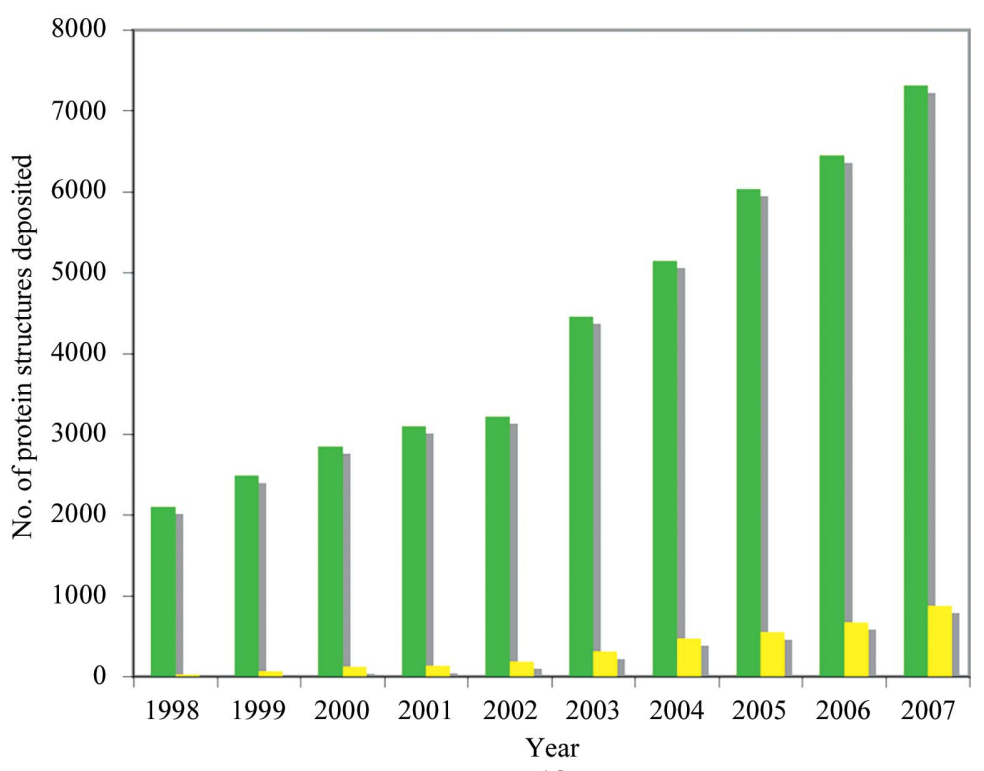

(d)

Figure 1

Incidences of SeMet use for phasing in the Protein Data Bank (PDB). (a) Pie chart showing the proportion of MAD-phased structures using SeMet (yellow) as a percentage of the total structures phased using MAD. (b) Proportion of SAD-phased structures using SeMet (yellow) as a percentage of the total SAD-phased structures. (c) Proportion of structural genomics (SGX) derived crystal structures solved using SeMet (yellow) as a percentage of the total number of SGX-derived crystal structures. $(d)$ Total number of crystal structures deposited each year (green), with the number solved using SeMet shown in yellow. Numbers were correct at the end of 2008 for $(a)-(c)$ and the end of 2007 for $(d)$. 
Table 1

Comparison of methods for prokaryal expression of SeMet-labelled protein.

\begin{tabular}{|c|c|c|c|}
\hline Met auxotroph, B834 & Met inhibition, BL21 & $\begin{array}{l}\text { No Met inhibition, defined LeMaster } \\
\text { medium + SeMet, BL21 }\end{array}$ & Auto-induction, BL21 \\
\hline $\begin{array}{l}\text { Slow growth, longer lag phase, } \\
\text { low cell density }\end{array}$ & $\begin{array}{l}\text { Closer to LB levels of growth, } \\
\text { good cell density }\end{array}$ & $\begin{array}{l}\text { Close to LB levels of growth, } \\
\text { good cell density }\end{array}$ & $\begin{array}{l}\text { High cell density, ease of culture, } \\
\text { good growth; takes a long time ( } 48 \mathrm{~h})\end{array}$ \\
\hline $\begin{array}{l}\text { Poor yields, } \sim 20 \% \text { that of } \\
\quad \text { unlabelled }\end{array}$ & $\begin{array}{l}\text { OK yields, } \sim 30-80 \% \text { that of } \\
\text { unlabelled }\end{array}$ & $\begin{array}{l}\text { Good yields, } \sim 50-70 \% \text { that of } \\
\text { unlabelled }\end{array}$ & $\begin{array}{l}\text { Good recovery of protein, often } \\
\text { better than induced unlabelled }\end{array}$ \\
\hline$\sim 100 \%$ incorporation of SeMet & $>90 \%$ incorporation of SeMet & $>90 \%$ incorporation of SeMet & $>90 \%$ incorporation of SeMet \\
\hline
\end{tabular}

are added to the culture shortly $(\sim 10-15 \mathrm{~min})$ before induction (for recipes, see Doublié, 2007, and the end of this review). The yield of protein is often better than with the auxotroph, the cell density is greater and the growth levels are closer to those obtained using LB for native growth.

Another effective means of achieving SeMet incorporation is to grow the culture directly in defined LeMaster media without any requirement for methionine-biosynthesis inhibition (LeMaster \& Richards, 1985; Bravo et al., 1998). This method also leads to good growth and yields and high incorporation rates. It is also less involved in terms of media preparation.

In addition, it has recently been reported that the use of auto-inducing media with a non-auxotrophic strain is also a viable system for producing SeMet-labelled proteins (Studier, 2005). This system entails the transformation of cells and then culturing them in a smaller volume for greater aeration for a total of $\sim 24 \mathrm{~h}$ at a culture temperature of $310 \mathrm{~K}$ (increasing to $40 \mathrm{~h}$ or longer at lower growth temperatures such as 298 or 289 K; Sreenath et al., 2005; Doublié, 2007). This method generally leads to $>90 \%$ SeMet incorporation and has the advantage of high cell density and good recovery of protein. The disadvantages are the costs and preparation associated with the auto-inducing media and the length of time required for culture growth.

In short, the decision as to which experiment to execute depends on how much SeMet incorporation is required (i.e. how many ordered sites for substitution are predicted? Would only $90 \%$ incorporation be sufficient?), time constraints on the cell preparation (e.g. proximity of the next synchrotron trip!) and considerations for yield (i.e. how well the protein is expressed).

Table 1 summarizes the characteristics of each system. There are many excellent protocols for the expression of SeMet proteins in prokaryotic systems (Doublié, 1997, 2007) and a short set of notes is included at the end of this review.

\section{Eukaryotic systems}

\subsection{Baculovirus-infected insect-cell expression}

The most commonly used alternative to E. coli for the production of soluble recombinant protein is baculovirusinfected insect-cell expression (Possee, 1997). The advantages of this system include the incorporation of post-translational modifications such as phosphorylation and glycosylation and the greater solubility of some eukaryal proteins.
There are many examples of SeMet incorporation in insect cells for both secreted and intracellularly expressed proteins (Bellizzi et al., 1999; Fremont et al., 1998; Aricescu, Assenberg et al., 2006; McWhirter et al., 1999). In general, secreted proteins have a higher incorporation of SeMet than intracellularly expressed proteins. This is because when the Metcontaining medium is exchanged for SeMet medium, any unlabelled protein that has already been secreted is removed. However, in 2007 Cronin and coworkers reported a systematic study of SeMet-labelling proteins in baculovirus expressionvector systems in order to determine an optimal protocol for obtaining consistent and reliable SeMet-labelled protein for both intracellularly expressed and secreted proteins (Cronin et al., 2007). They found that the time of addition of SeMet was crucial for incorporation.

To summarize, SeMet should be added within the first $16 \mathrm{~h}$ post-infection for optimal substitution and there is a trade-off between the SeMet concentration in the medium and the yield of protein and level of SeMet incorporation. As with the situation in prokarya, the experimental decision depends on how much SeMet incorporation is required and considerations for yield. Table 2 summarizes these findings and a basic protocol for insect-cell expression is listed at the end of this review.

\subsection{Yeast}

As an alternative to prokaryal systems, yeast is an attractive host as it is relatively inexpensive and simple to culture, often yielding $2 \mathrm{mg}$ of purified unlabelled protein per litre of cell culture (Martzen et al., 1999; Gelperin et al., 2005). There are also examples of the production of SeMet-labelled proteins in both Pichia pastoris and Saccharomyces cerevisiae (Worthylake et al., 1998; Macbeth et al., 2005; Jidenko et al., 2005; Bushnell et al., 2001; Larsson et al., 2002). However, the drawback to the system has been the cytotoxicity of SeMet and although some successful reports have been published, the incorporation of selenium has hovered around the $50 \%$ mark. This was not sufficient to phase the RNA polymerase II complex, but proved useful for chain tracing (Bushnell et al., 2001). Recently, Malkowski and coworkers have reported that blocking $S$-adenosylmethionine (SAM) biosynthesis allows higher SeMet incorporation (>95\%), following their initial hypothesis that the reason for the toxicity of selenium is the conversion of SAM to the seleno-derivative (Malkowski et al., 2007). Consequently, they developed an SeMet-resistant strain of $S$. cerevisiae which should prove useful for structural 
Table 2

Comparison of strategies for insect-cell expression of SeMet-labelled protein.

\begin{tabular}{lll}
\hline SeMet $\left(\mathrm{mg} \mathrm{l}^{-1}\right)$ & $\begin{array}{l}\text { Yield (\% that of } \\
\text { unlabelled expression) }\end{array}$ & $\begin{array}{l}\text { Incorporation } \\
\text { of SeMet }(\%)\end{array}$ \\
\hline $50-100$ & $\sim 50$ & $\sim 50$ \\
200 & $\sim 20$ & $>70$ \\
\hline
\end{tabular}

studies. Their initial reports suggest yields of SeMet-labelled protein of between 30 and $60 \%$ of that obtained in unlabelled expression. Finally, although not a recombinant technique per $s e$, the complete replacement of Met with SeMet has recently been reported in yeast by growing yeast entirely on SeMet, suggesting a viable approach for purifying SeMet-labelled yeast proteins from source (Ouerdane \& Mester, 2008).

\subsection{Mammalian}

For production, some proteins require conditions that are as close to native as possible. In such cases, stably transfected mammalian cell lines are used as expression hosts for the protein of interest. In individual cases, these hosts have been adapted to produce SeMet-labelled proteins. For example, Chinese Hamster Ovary ( $\mathrm{CHO}$ ) cells were used to achieve 93\% SeMet incorporation for a secreted protein (Lustbader et al., 1995), while HEK293 cells achieved 60\% incorporation for a secreted protein (Aricescu, Lu et al., 2006). In 2006, Barton and coworkers described a method for efficient SeMet labelling in mammalian cells, which entailed depleting the medium of methionine for $12 \mathrm{~h}$ prior to addition of SeMet at $60 \mathrm{mg} \mathrm{l}^{-1}$ and culturing for a further $48 \mathrm{~h}$ for roller-bottle cultures or for $72 \mathrm{~h}$ for dishes. In their test cases, this yielded $60-80 \%$ of the amount of protein produced during unlabelled expression with greater than $90 \%$ SeMet incorporation (Barton et al., 2006).

In addition to the prokaryal and eukaryal systems reviewed above, the use of cell-free synthesis has been reported as an alternative (Kigawa et al., 2002) and, impressively, the labelling of an entire virus by finding a suitable host has recently been reported (Kivela et al., 2008). These advances suggest that the use of selenium for structure determination is only set to increase.

\section{Considerations}

\subsection{Oxidation state}

It has been reported that oxidized SeMet has an increased magnitude in its absorption edge compared with reduced SeMet (Smith \& Thompson, 1998). Subsequently, several groups have exploited deliberate oxidation of selenium in order to maximize the anomalous signal. The structure of the TolC receptor was solved after treatment of the protein with $0.1 \%$ hydrogen peroxide for $10 \mathrm{~s}$, although this would not be a useful treatment for the majority of enzymes (Sharff et al., 2000). Thomazeau and coworkers reported the phasing of threonine synthase using oxidized selenium, in which peroxide was not employed (Thomazeau et al., 2001). Certainly, this is something that is worth considering if there are few or disordered methionines in the crystal. However, a note of caution is that an oxidized SeMet would be expected to be more radiation-sensitive than its reduced form, radiation-induced decay of the anomalous signal being one of the problems in using selenium as a phasing atom (Holton, 2007). Including a strong reducing agent such as tris(2-carboxyethyl)phosphine (TCEP) to push the SeMet back into a reduced state is also useful. The important point is that the state of the SeMet should be uniform, otherwise the Se $K$ edge moves to a higher energy, smudging the edge.

\subsection{Occupancy}

The purpose of recombinantly incorporating heavy atoms is for eventual structure determination. For this to be successful, the anomalous scatterer needs to provide sufficient phasing power. Predicting the strength of an anomalous signal can be useful in deciding what levels of incorporation of heavy atom will be minimally required for a successful phasing experiment (Garman \& Murray, 2003; http://skuld.bmsc.washington.edu/ scatter/AS_signal.html). In general, the heavier the atom the larger the signal and the easier it will be to measure. As selenium is actually fairly small by heavy-atom standards, it is important to maximize the phasing power. This can be achieved through optimum occupancy. Occupancy is defined as the fraction of unit cells in a crystal that contain the atom in question. If occupancy is low it may be difficult to locate the heavy atom because of noise in the map resulting from approximations inherent in the data. This inevitably reduces the phasing power of the heavy atom and in the case of the RNA polymerase II complex expressed in yeast a $50 \%$ incorporation of SeMet was not sufficient to phase the structure (Bushnell et al., 2001). Thus, ensuring maximum incorporation of selenium will provide better phasing power for structure determination.

\subsection{Not enough methionines?}

Although the majority of proteins contain methionine (estimated at 80\%; Boggon \& Shapiro, 2000), for SeMet labelling to be sufficient for phasing the substructure there must be enough ordered sites. If the protein in question has a low level of methionine content, there are strategies that can be employed to maximize the phasing power of the experiment. Firstly, at the DNA level, extra methionines can be engineered in. Leucine and isoleucine are good candidates for substitution given their hydrophobic nature and their likelihood of being ordered in the core of the protein. Homologues, even remote ones, can provide a useful guide to engineering in methionines. This strategy can also prove useful if sequence assignment is problematic.

Secondly, double labelling of the protein by using selenocysteine in combination with SeMet can be employed (Strub et al., 2003). This increases the cost of the experiment and can also limit the yield, but does allow the production of more anomalous atoms in the crystal. 
Finally, another option is to use the larger, although significantly less stable, analogue telluromethionine. When successful, this substitution provides a strong anomalous signal and therefore significant phasing power (Budisa et al., 1997).

\section{Measuring the incorporation of selenium}

After the efforts expended to achieve SeMet incorporation, it is essential to verify that is has occurred prior to crystallization and data collection. There are several methods by which to check the substitution of Met by SeMet (and Cys by SeCys). Mass spectrometry is the primary technique and is very effective. It can be used for peptide-fragment analysis to measure the difference in mass between the peptides yielded from tryptic digests of unlabelled and labelled protein. Intact mass analysis is also sensitive enough to measure the difference in mass between labelled and unlabelled protein and can also give an idea as to the oxidation state of the seleniums in solution. In the rare cases where a protein does not fly well in the mass-spectrometry experiment, quantitative amino-acid analysis can be used to measure the loss of methionine, with the assumption that it has been replaced by SeMet. MicroPIXE (proton-induced X-ray emission) is another useful quantitative tool for the measurement of selenium content in a protein sample (Garman, 1999). A fluorescence scan of the protein either in solution or in the crystalline form will also detect selenium in the sample and most modern beamlines incorporate the fluorescence emission spectrum as a matter of a course, revealing the elemental composition of the sample.

\section{Crystallization}

One of the major advantages of recombinantly introducing an anomalous scatterer into a protein is the fact that the resulting crystal will be used to obtain all data, making the heavy-atom derivative isomorphous with the protein structure. In the majority of cases, crystallization of an SeMet-labelled protein occurs under identical or very similar conditions to the native protein. If sufficient material is obtained, then re-screening for crystallization conditions is advisable as there are instances in which better diffracting crystals or new crystal forms have been obtained using the labelled protein. If this is not successful, cross-seeding with the unlabelled crystals is a very useful technique (see, for example, Love et al., 2003) and is especially so when the SeMet-labelled protein yields are low. In general, SeMet-substituted proteins tend to be a little less soluble than their native counterparts owing to increased hydrophobicity and therefore lowering the protein or precipitant concentration is a good place to start if identical conditions do not yield crystals. The crystals themselves are often slightly less stable than the native crystals, probably owing to the sensitivity of selenium to oxidation compared with sulfur. Cryocooling the crystals as soon as they have grown is one way around this problem and adding a strong reducing agent, even at the point of mounting the crystal (providing it survives), will also aid the stability.

\section{Conclusions}

In summary, the use of recombinant SeMet labelling for structure determination was a huge step forward in experimental phasing and is now a commonly used technique. The advances in expression systems outlined above have made it an even more attractive technique for phasing, and the numbers of SeMet MAD/SAD experimentally phased structures is only going to increase. There are many useful recipes and protocols for SeMet (and SeCys) labelling of proteins (Barton et al., 2006; Kivela et al., 2008; Cronin et al., 2007; Strub et al., 2003; Doublié, 2007, 1997); listed below are some notes to get you started.

\section{Materials and methods}

\subsection{Prokaryal expression using a methionine auxotroph}

Transform B834 (DE3) cells (Invitrogen, Stratagene, Novagen) with expression vector.

Grow overnight culture in LB media at $310 \mathrm{~K}$, shaking at 150-200 rev $\min ^{-1}$.

Spin down cells gently $(2000 \mathrm{~g})$ and wash the pelleted cells with M9 minimal media (for recipes, see Doublié, 2007).

Inoculate 11 culture(s) of M9 minimal media containing appropriate antibiotics, 5-10 $\mathrm{g} \mathrm{l}^{-1}$ glucose, all amino acids except Met at $40 \mathrm{mg} \mathrm{l}^{-1}$, L-SeMet at $50 \mathrm{mg} \mathrm{l}^{-1}, 2 \mathrm{mg} \mathrm{l}^{-1}$ thiamine and $2 \mathrm{mg} \mathrm{l}^{-1}$ biotin.

Induce as for native.

Harvest as for native.

Expect the time taken to reach mid-log phase to be $12-18 \mathrm{~h}$.

When purifying the protein, degas all buffers (unless aiming for deliberate selenium oxidation) and add a reducing agent such as dithiothreitol, $\beta$-mercaptoethanol or tris(2-carboxyethyl)phosphine (TCEP).

\subsection{Prokaryal expression inhibiting methionine biosynthesis}

Grow overnight culture in LB medium at $310 \mathrm{~K}$, shaking at 150-200 rev $\min ^{-1}$.

Spin down cells gently $(2000 g)$ and wash the pelleted cells with M9 minimal media.

Inoculate 11 culture(s) of M9 minimal medium containing appropriate antibiotics and $5 \mathrm{~g} \mathrm{l}^{-1}$ glucose.

At mid-log phase add $100 \mathrm{mg} \mathrm{l}^{-1}$ each of phenylalanine, lysine and threonine, $50 \mathrm{mg} \mathrm{l}^{-1}$ each of leucine, isoleucine, valine and $\mathrm{L}-\mathrm{SeMet}$.

Induce $15 \mathrm{~min}$ after addition of amino acids.

Harvest as for native.

Purify with degassed buffers and reducing agent.

\subsection{Prokaryal expression in LeMaster medium}

Grow overnight culture in LB medium at $310 \mathrm{~K}$, shaking at 150-200 rev $\min ^{-1}$.

Inoculate 11 culture(s) of defined LeMaster medium (LeMaster \& Richards, 1985) containing appropriate antibiotics.

Induce as for native. 
Harvest as for native.

Purify with degassed buffers and reducing agent.

\subsection{Prokaryal expression using auto-inducing media}

See Studier (2005), Sreenath et al. (2005) and Doublié (2007) for protocols using autoinduction media.

Harvest as for native.

Purify with degassed buffers and reducing agent.

\subsection{Eukaryal expression in insect cells}

Infect cells in methionine-containing media.

$16 \mathrm{~h}$ post-infection, change media to methionine-free media and supplement with 50-200 $\mathrm{mg} \mathrm{l}^{-1}$ (see Table 2) L-SeMet.

Culture for $48 \mathrm{~h}$ post-infection.

Harvest as for native.

Purify with degassed buffers and reducing agent.

\section{References}

Aricescu, A. R., Assenberg, R. et al. (2006). Acta Cryst. D62, 11141124.

Aricescu, A. R., Lu, W. \& Jones, E. Y. (2006). Acta Cryst. D62, $1243-$ 1250.

Barton, W. A., Tzvetkova-Robev, D., Erdjument-Bromage, H., Tempst, P. \& Nikolov, D. B. (2006). Protein Sci. 15, 2008-2013.

Bellizzi, J. J., Widom, J., Kemp, C. W. \& Clardy, J. (1999). Structure, 7, R263-R267.

Boggon, T. J. \& Shapiro, L. (2000). Structure, 8, R143-R149.

Bravo, J., Staunton, D., Heath, J. K. \& Jones, E. Y. (1998). EMBO J. 17, 1665-1674.

Budisa, N., Karnbrock, W., Steinbacher, S., Humm, A., Prade, L., Neuefeind, T., Moroder, L. \& Huber, R. (1997). J. Mol. Biol. 270, 616-623.

Bushnell, D. A., Cramer, P. \& Kornberg, R. D. (2001). Structure, 9, R11-R14.

Chandonia, J. M. \& Brenner, S. E. (2006). Science, 311, 347-351.

Cowie, D. B. \& Cohen, G. N. (1957). Biochim. Biophys. Acta, 26, 252-261.

Cronin, C. N., Lim, K. B. \& Rogers, J. (2007). Protein Sci. 16, $2023-$ 2029.

Doublié, S. (1997). Methods Enzymol. 276, 523-530.

Doublié, S. (2007). Methods Mol. Biol. 363, 91-108.

Fremont, D. H., Crawford, F., Marrack, P., Hendrickson, W. A. \& Kappler, J. (1998). Immunity, 9, 385-393.

Garman, E. (1999). Structure, 7, R291-R299.

Garman, E. \& Murray, J. W. (2003). Acta Cryst. D59, 1903-1913.

Gelperin, D. M., White, M. A., Wilkinson, M. L., Kon, Y., Kung, L. A., Wise, K. J., Lopez-Hoyo, N., Jiang, L., Piccirillo, S., Yu, H., Gerstein, M., Dumont, M. E., Phizicky, E. M., Snyder, M. \& Grayhack, E. J. (2005). Genes Dev. 19, 2816-2826.

Hendrickson, W. A., Horton, J. R. \& LeMaster, D. M. (1990). EMBO J. 9, 1665-1672.
Holton, J. M. (2007). J. Synchrotron Rad. 14, 51-72.

Jidenko, M., Nielsen, R. C., Sorensen, T. L., Moller, J. V., le Maire, M., Nissen, P. \& Jaxel, C. (2005). Proc. Natl Acad. Sci. USA, 102, 1168711691.

Kigawa, T., Yamaguchi-Nunokawa, E., Kodama, K., Matsuda, T., Yabuki, T., Matsuda, N., Ishitani, R., Nureki, O. \& Yokoyama, S. (2002). J. Struct. Funct. Genomics, 2, 29-35.

Kivela, H. M., Abrescia, N. G., Bamford, J. K., Grimes, J. M., Stuart, D. I. \& Bamford, D. H. (2008). J. Struct. Biol. 161, 204-210.

Koon, N., Squire, C. J. \& Baker, E. N. (2004). Acta Cryst. D60, 11671169.

Larsson, A. M., Ståhlberg, J. \& Jones, T. A. (2002). Acta Cryst. D58, 346-348.

Leahy, D. J., Hendrickson, W. A., Aukhil, I. \& Erickson, H. P. (1992). Science, 258, 987-991.

LeMaster, D. M. \& Richards, F. M. (1985). Biochemistry, 24, 7263 7268.

Li, Y., Chirgadze, D. Y., Bolanos-Garcia, V. M., Sibanda, B. L., Davies, O. R., Ahnesorg, P., Jackson, S. P. \& Blundell, T. L. (2008). EMBO J. 27, 290-300.

Love, C. A., Harlos, K., Mavaddat, N., Davis, S. J., Stuart, D. I., Jones, E. Y. \& Esnouf, R. M. (2003). Nature Struct. Biol. 10, 843-848.

Lustbader, J. W., Wu, H., Birken, S., Pollak, S., Gawinowicz Kolks, M. A., Pound, A. M., Austen, D., Hendrickson, W. A. \& Canfield, R. E. (1995). Endocrinology, 136, 640-650.

Macbeth, M. R., Schubert, H. L., Vandemark, A. P., Lingam, A. T., Hill, C. P. \& Bass, B. L. (2005). Science, 309, 1534-1539.

Malkowski, M. G., Quartley, E., Friedman, A. E., Babulski, J., Kon, Y., Wolfley, J., Said, M., Luft, J. R., Phizicky, E. M., DeTitta, G. T. \& Grayhack, E. J. (2007). Proc. Natl Acad. Sci. USA, 104, 6678-6683.

Martzen, M. R., McCraith, S. M., Spinelli, S. L., Torres, F. M., Fields, S., Grayhack, E. J. \& Phizicky, E. M. (1999). Science, 286, 11531155.

McWhirter, S. M., Pullen, S. S., Holton, J. M., Crute, J. J., Kehry, M. R. \& Alber, T. (1999). Proc. Natl Acad. Sci. USA, 96, 8408-8413.

Ouerdane, L. \& Mester, Z. (2008). J. Agric. Food Chem. 56, 11792 11799.

Possee, R. D. (1997). Curr. Opin. Biotechnol. 8, 569-572.

Quevillon-Cheruel, S., Leulliot, N., Meyer, P., Graille, M., Bremang, M., Blondeau, K., Sorel, I., Poupon, A., Janin, J. \& van Tilbeurgh, H. (2004). J. Biol. Chem. 279, 619-625.

Sharff, A. J., Koronakis, E., Luisi, B. \& Koronakis, V. (2000). Acta Cryst. D56, 785-788.

Smith, J. L. \& Thompson, A. (1998). Structure, 6, 815-819.

Sreenath, H. K., Bingman, C. A., Buchan, B. W., Seder, K. D., Burns, B. T., Geetha, H. V., Jeon, W. B., Vojtik, F. C., Aceti, D. J., Frederick, R. O., Phillips, G. N. Jr \& Fox, B. G. (2005). Protein Expr. Purif. 40, 256-267.

Strub, M.-P., Hoh, F., Sanchez, J.-F., Strub, J. M., Böck, A., Aumelas, A. \& Dumas, C. (2003). Structure, 11, 1359-1367.

Studier, F. W. (2005). Protein Expr. Purif. 41, 207-234.

Thomazeau, K., Curien, G., Thompson, A., Dumas, R. \& Biou, V. (2001). Acta Cryst. D57, 1337-1340.

Van Duyne, G. D., Standaert, R. F., Karplus, P. A., Schreiber, S. L. \& Clardy, J. (1993). J. Mol. Biol. 229, 105-124.

Worthylake, D. K., Prakash, S., Prakash, L. \& Hill, C. P. (1998). J. Biol. Chem. 273, 6271-6276. 